\title{
HIV Disparities in a US and Foreign-Born Cohort in Urban United States
}

Helena Akua Kwakwa*, Rahab Wahome and Sophia Bessias

Department of Public Health, HIV Clinical Services, Ambulatory Health Services, Philadelphia, USA

\begin{abstract}
Background: As we strive to reduce disparities in the implementation of the US National HIVIAIDS Strategy, we must understand HIV disparities as they exist in all US populations, including the foreign-born. We evaluate disparities in HIV prevalence in a US and foreign-born cohort in Philadelphia.
\end{abstract}

Methods: Comparative analyses were conducted using data from questionnaires paired with HIV test results for individuals undergoing HIV testing in Philadelphia between 2007 and 2011. Descriptive analyses were conducted by gender and world region of origin.

Results: Of 14,216 participants, $76.2 \%$ were US-born and $59 \%$ female. Caribbean men, $3.6 \%$ of the cohort, constituted $11.4 \%$ of the HIV- positive. Among women, Africans, $3.0 \%$ of the cohort constituted $4.5 \%$ of the HIVpositive. No disparities by race/ethnicity were found in the US-born cohort.

Conclusions: In this global population in Philadelphia, HIV disparities were found to occur by world region of birth and gender. The foreign-born must be included in analyses of the domestic epidemic that drive prevention strategies, policy and resource allocation.

Keywords: HIV; Foreign-born; Disparities; US

\section{Introduction}

Of the estimated 1.1 million individuals living with HIV in the US, [1] a significant and growing percentage is foreign-born [2,3]. In the first published national analysis of the foreign-born population in the US with HIV, conducted in 46 states between 2007 and 2010 the foreignborn constituted $16.2 \%$ of the HIV-positive person (although they accounted for $13 \%$ of the US population overall). [2] In an unrelated analysis of the contribution of the African-born to the domestic HIV epidemic, Kerani et al. found that the African-born constituted 3.8\% of the HIV-positive in 8 US jurisdictions, although they accounted for $0.6 \%$ of the population overall [4]. While analyses of disparities in the impact and prevalence of HIV have been integral to our understanding of the domestic epidemic, the US-resident foreign-born are seldom included in such analyses as a distinct group.

The growing population of the foreign-born must factor into our approaches to all aspects of the 2015 National HIV/AIDS Strategy, [5] including reducing disparities and health inequities. Philadelphia has been described by the Brookings Institute as a "re-emerging gateway for immigrants" [6]. In Philadelphia, the foreign-born population increased in the 1990 s by $30 \%$, from 104,816 to 136,000 [7]. Nine percent of the population in 2000, the foreign-born constituted 12.2\% of Philadelphia residents in 2014 [8]. Yet despite their growing numbers, there is scant information on the impact of the foreign born on the HIV epidemic locally. We seek to understand disparities in HIV prevalence rates in persons undergoing HIV rapid testing in Philadelphia, evaluating prevalence rates by world region of origin as well as by gender.

\section{Methods}

Comparative analyses were conducted using data from questionnaires paired with HIV test results for individuals undergoing rapid HIV testing in the walk-in clinics of Philadelphia's city health centers. Operated by the Philadelphia Department of Public Health, these Federally Qualified Health Center look-alike neighborhood facilities provide primary care services to the residents of Philadelphia regardless of their insurance status or ability to pay. The city health centers serve as a safety net for Philadelphia residents.
Individuals seeking care between 2007 and 2011 were offered HIV rapid testing. From those consenting to testing, data collected included demographics, country of origin, HIV testing history and risk behaviors. This study was exempted by the Institutional Review Board of the City of Philadelphia.

Descriptive analyses were conducted by gender and by world region of origin. Chi square and students $t$ tests were performed to assess risk behavior differences by world region of origin for categorical and continuous variables respectively. All analyses were conducted using Statistical Analysis Software (SAS) 9.2; SAS Institute, Cary, NC. In this study "foreign-born" was a purely geographic term defined as born outside the continental US. US territories were designated according to the geographic world region in which they are located. In the absence of any Canadians from this cohort, Mexico was analyzed as the sole foreign entity in North America.

\section{Results}

During the 4-year period between 2007 and 2011, 14,216 unduplicated individuals underwent HIV rapid testing at the city health centers of Philadelphia. Among these, a majority $(76.2 \%)$ was US-born, and $23.8 \%(4,214)$ were foreign-born per the study definition. Of the cohort undergoing testing, $77 \%$ lived below the federal poverty level.

*Corresponding author: Helena Akua Kwakwa, Department of Public Health, HIV Clinical Services, Philadelphia Department of Public Health, Ambulatory Health Services, 500 South Broad Street, Philadelphia, PA, 19146, USA, Tel: 2156856769 ; Fax: 2156876732; E-mail: hkwakwa@aol.com

Received September 24, 2015; Accepted October 19, 2015; Published October 25,2015

Citation: Kwakwa HA, Wahome R, Bessias S (2015) HIV Disparities in a US and Foreign-Born Cohort in Urban United States. J AIDS Clin Res 6: 515 doi:10.4172/2155-6113.1000515

Copyright: (c) 2015 Kwakwa HA, et al. This is an open-access article distributed under the terms of the Creative Commons Attribution License, which permits unrestricted use, distribution, and reproduction in any medium, provided the original author and source are credited. 


\begin{tabular}{|l|c|c|c|c|c|}
\hline \multirow{2}{*}{$\begin{array}{l}\text { World region of origin } \\
\text { (n) }\end{array}$} & \multicolumn{2}{|c|}{ Gender (\%) } & \multicolumn{2}{|c|}{ Age } & Previous HIV \\
testing (\%)
\end{tabular}

Table 1: Demographic, nativity and previous HIV testing characteristics of individuals undergoing HIV rapid testing at Philadelphia's city health centers, 2007$2011(n=14,216)$.

\section{Region of birth}

Table 1 shows the world region of origin of the individuals undergoing HIV rapid testing as a part of this study. Among the foreignborn cohort, the largest numbers were from the Caribbean $(31 \%)$ and Asia (25\%). The top 10 individual countries represented collectively constituted $50.9 \%$ of the foreign-born cohort. The vast majority of the Sub Saharan African cohort (93\%) was West African in origin. Among the US-born cohort $83.5 \%$ were non-Hispanic black.

\section{Demographics and HIV testing history}

Table 1 shows the gender, age and HIV testing history of the entire cohort, by world region of birth. For each region represented, women outnumbered men in this population, with higher proportions of the foreign-born $(67 \%)$ being female compared to the US cohort $(51 \%$, $\mathrm{p}<0.001)$. Median age did not vary significantly by region of origin. With a median age of 28, Europeans trended slightly younger, while the Caribbean cohort was the oldest with a median age of 36 .

A substantial majority of the cohort reported having had at least one HIV test ever in the past. The US-born cohort reported higher rates of ever having been tested (78\%) than the foreign-born cohort $(59.3 \%, \mathrm{p}<0.001)$. The only world region with a previous testing rate comparable to that of the US was Sub-Saharan Africa (76.3\%). All other regions reported significantly lower rates of ever having been tested compared to the continental US. Among Asians, Europeans, and Middle Easterners and North Africans, fewer than half had ever been tested for HIV. Among the US-born, previous HIV testing rates varied by race and ethnicity. African Americans reported the highest previous testing rates (78.4\%), followed by Hispanic Americans (70.4\%). European Americans reported the lowest rates of previous testing (59.0\%) of the US-born ( $\mathrm{p}<0.05$ compared with non-European Americans).

\section{HIV Seroprevalence Rates by Gender}

As shown in Table 2, the HIV seroprevalence rate for the entire cohort was $0.6 \%$. This figure masks important differences by world region of origin and by gender. The overall male prevalence rate was $1.0 \%$ and the rate among this global female cohort was $0.4 \%$. This gender difference was greater for the foreign-born cohort, with a $1.4 \%$ rate among foreign-born men, and $0.3 \%$ among women born outside the continental US $(\mathrm{p}=0.001)$. The gender difference was greatest in the Caribbean cohort, where the prevalence rate was $1.9 \%$ and $0.3 \%$ among men and women respectively $(\mathrm{p}=0.03)$. It was least in the Sub Saharan African cohort, among whom the male prevalence rate was $1.2 \%$, and the female $1.0 \%(\mathrm{p}=0.63)$. US-born men had a higher prevalence rate of $0.9 \%$ compared to $0.5 \%$ for US-born women $(\mathrm{p}<0.05)$.

Among the US-born the difference in prevalence rates by gender were greater than across ethnicities. By ethnicity, rates were highest at $0.5 \%$ among black women, $0.4 \%$ for white women, and $0.3 \%$ for Hispanic women. Among US-born men, rates trended slightly higher at $0.9 \%$ for black men than for white or Hispanic men, at $0.8 \%$ each.

\section{HIV Disparities by world region and gender}

Table 2 shows the disparities in prevalence rate as indicated by the representation of each world region in the HIV-positive cohort identified in this testing program, compared to their representation in the total population tested. In general men were overrepresented in the HIV-positive group with the sole exception of Asian men among whom none tested positive. On the other hand, women were generally underrepresented among the HIV-positive cohort, with the exception being Sub Saharan African women, who constituted 3\% of the population tested and $4.5 \%$ of those testing positive.

The group most overrepresented among the HIV-positive cohort was Caribbean men. Only $3.6 \%$ of the population tested were Caribbean men, yet they constituted $11.4 \%$ of those testing positive for HIV. The relatively high rate of HIV among Caribbean men was driven by a small number of men who have sex with men (MSM). Almost half (45\%) of Caribbean MSM testing positive self-identified as MSM. Among the Caribbean MSM the HIV prevalence rate was 50\%, in stark contrast to the rate of $1.1 \%$ among Caribbean non-MSM. Compared with US men, the odds ratio for HIV infection in Caribbean men was 2.69 (95\% CI 1.56-4.63, $\mathrm{p}<0.001)$. The rate of HIV among Caribbean

\begin{tabular}{|c|c|c|c|c|}
\hline World region & Prevalence & $\begin{array}{c}\text { Number } \\
\text { tested }\end{array}$ & $\begin{array}{c}\text { Percentage of } \\
\text { population tested }\end{array}$ & $\begin{array}{l}\text { Percentage of HIV- } \\
\text { positive cohort }\end{array}$ \\
\hline $\begin{array}{l}\text { Asia } \\
\text {-Female } \\
\text {-Male }\end{array}$ & $\begin{array}{c}0.09 \\
0.12 \\
0\end{array}$ & $\begin{array}{c}1,066 \\
831 \\
235\end{array}$ & $\begin{array}{l}7.5 \\
5.8 \\
1.7\end{array}$ & $\begin{array}{c}1.1 \\
1.1 \\
0\end{array}$ \\
\hline $\begin{array}{l}\text { Caribbean } \\
\text {-Female } \\
\text {-Male }\end{array}$ & $\begin{array}{l}0.9 \\
0.3 \\
1.9\end{array}$ & $\begin{array}{c}1,289 \\
773 \\
516\end{array}$ & $\begin{array}{l}9.1 \\
5.4 \\
3.6\end{array}$ & $\begin{array}{c}13.6 \\
2.3 \\
11.4\end{array}$ \\
\hline $\begin{array}{l}\text { Mexico } \\
\text {-Female } \\
\text {-Male }\end{array}$ & $\begin{array}{c}0.5 \\
0 \\
1.3\end{array}$ & $\begin{array}{c}219 \\
140 \\
79\end{array}$ & $\begin{array}{l}1.5 \\
1.0 \\
0.6\end{array}$ & $\begin{array}{c}1.1 \\
0 \\
1.1\end{array}$ \\
\hline $\begin{array}{l}\text { Sub Saharan Africa } \\
\text {-Female } \\
\text {-Male }\end{array}$ & $\begin{array}{l}1.0 \\
1.0 \\
1.2\end{array}$ & $\begin{array}{l}669 \\
421 \\
248\end{array}$ & $\begin{array}{l}4.7 \\
3.0 \\
1.7\end{array}$ & $\begin{array}{l}8.0 \\
4.5 \\
3.4\end{array}$ \\
\hline $\begin{array}{l}\text { All foreign-born } \\
\text {-Female } \\
\text {-Male }\end{array}$ & $\begin{array}{l}0.5 \\
0.3 \\
1.4\end{array}$ & $\begin{array}{l}4,214 \\
2,823 \\
1,391\end{array}$ & $\begin{array}{c}29.6 \\
20.5 \\
8.2\end{array}$ & $\begin{array}{c}23.8 \\
8.1 \\
17.4 \\
\end{array}$ \\
\hline $\begin{array}{l}\text { US } \\
\text {-Female } \\
\text {-Male } \\
\text { Black female } \\
\text { Black male } \\
\text { White female } \\
\text { White male } \\
\text { Hisp female } \\
\text { Hisp male }\end{array}$ & $\begin{array}{l}0.7 \\
0.5 \\
0.9 \\
0.5 \\
0.9 \\
0.4 \\
0.8 \\
0.3 \\
0.8\end{array}$ & $\begin{array}{c}10,002 \\
5,397 \\
4,605 \\
4,469 \\
3,792 \\
506 \\
415 \\
422 \\
398\end{array}$ & $\begin{array}{c}70.0 \\
38.5 \\
32.8 \\
32.2 \\
27.3 \\
3.4 \\
2.8 \\
2.8 \\
2.6\end{array}$ & $\begin{array}{l}76.1 \\
29.1 \\
52.3 \\
24.4 \\
39.5 \\
2.3 \\
3.5 \\
1.1 \\
3.5\end{array}$ \\
\hline $\begin{array}{l}\text { Global } \\
\text {-Female } \\
\text {-Male }\end{array}$ & $\begin{array}{l}0.6 \\
0.4 \\
1.0\end{array}$ & $\begin{array}{c}14,216 \\
8,387 \\
5,824\end{array}$ & $\begin{array}{c}100 \\
59 \\
41\end{array}$ & $\begin{array}{l}100 \\
100 \\
100\end{array}$ \\
\hline
\end{tabular}

Table 2: HIV prevalence rate by world region of origin and by gender, and relative contribution (compared to contribution to population tested) to overall HIV prevalence rate by world region and by gender. 
women was substantially lower than in their male counterparts. Second in overrepresentation in the positive group was Sub Saharan African men who accounted for $1.7 \%$ of those tested and $3.4 \%$ of the positive. Compared with US men, the odds ratio for HIV infection in Sub Saharan African men was 1.27 (95\% CI 0.46-3.51, p=0.69). Sub Saharan African women were 3\% of those tested, but constituted $4.5 \%$ of the positive. In comparison to US women, the odds ratio for HIV infection in Sub Saharan African women was 2.94 (95\% CI 1.21-7.14, $\mathrm{p}=0.02$ ). Sub Saharan Africans were the only group with both sexes overrepresented among the HIV-positive cohort.

As with most other world regions, US-born women were underrepresented and US-born men overrepresented among the HIV-positive, this pattern holding true for black, white and Hispanic Americans. Prevalence rates for black, white and Hispanic men were $0.9,0.8$ and $0.8(\mathrm{p}=0.06)$. A similar pattern was noted for black, white and Hispanic women with rates of $0.5,0.4$ and $0.3(\mathrm{p}=0.08)$ respectively

\section{HIV Risk behaviors}

HIV transmission risk for the entire cohort was predominantly heterosexual, with greater than $90 \%$ of foreign-born and US-born cohorts, both male and female, reporting sexual preference as heterosexual. Six percent of European men, 5\% of US-born men and $4 \%$ of Caribbean men noted sex with men in the twelve months prior to their HIV testing.

Exchange of sex for drugs or money was infrequently reported among women and a more common practice reported by men from each world region with the exception of the US where $6.7 \%$ of each gender reported engaging in the exchange of sex for drugs or money, and North Africa and the Middle East where no exchange of sex for drugs or money was noted by either men or women. For other world regions of birth, percentages of women exchanging sex for drugs or money ranged from zero for Mexican women and $0.2 \%$ for Asian women, to $1.1 \%$ for Sub-Saharan African women. The men who exchanged sex for drugs or money the least were Caribbean men (3.7\%); those reporting the practice the most, Sub-Saharan African men (5.9\%).

Illicit drugs were used infrequently among the population, and rarely injected. The most commonly used drug was cocaine which with few exceptions was smoked or snorted. Cocaine use was reported in 9.6\% of European men and $5.8 \%$ of Caribbean men. There was less use among Asian (2.1\%), North African (3.1\%) and Mexican men (4.2\%), and none among Sub-Saharan African and Latin American men. This contrasted with $11.8 \%$ reported cocaine use among US-born men in this cohort. Among women, cocaine use was rare, at less than $2 \%$ in each world region, with the sole exception of the US. Nine percent of US-born women reported cocaine use. Heroin use was reported only among those born in the US, and then rarely $(1.0 \%$ and $0.5 \%$ among men and women respectively).

\section{Discussion}

Disparities in HIV prevalence are a well-recognized feature of the domestic epidemic, a reflection of a complex mix of contextual factors such as poverty, comorbid sexually transmitted infections, behaviors such as sexual concurrency and illicit drug use, and other factors $[9,10]$. The US resident foreign-born population studied in this paper shows patterns of HIV epidemiology reflective of neither their countries of origin nor the US, suggesting that they should perhaps be regarded as a third group with their HIV prevalence informed in part by factors from their country of origin, and in part by realities in their adopted country.
Among the foreign-born, patterns of immigration and settlement in the US may also play a role in disparities noted. HIV prevalence varies widely within regions by country, and within countries by specific location [11,12]. Hence varying reports on HIV prevalence among the foreign-born may be found by US residential geography depending on patterns of immigration and settlement. In a prevalence study conducted in Los Angeles (LA) Public STD Clinics, the highest HIV rates $(5.7 \%)$ were found among Sub Saharan African women, [13] contrasting sharply with the rate in this study of $1 \%$. Yet even amidst these differences consistent themes emerge such as higher rates among foreign-born individuals of color. On a national level, the CDC reports that the majority of foreign-born men with HIV were from Central America and the Caribbean, while their female counterparts were mostly from the Caribbean, Africa and Central America [14]. In Michigan and in New York City, the highest rates of diagnosis were found in Africans, followed by Central and South Americans [15,16]. In this current analysis from Philadelphia, the highest rates among women were found in those from Africa, and in men, the Caribbean.

Studies of disparities in HIV prevalence also show some important trends. Among the HIV-positive in King County, Washington State, $57 \%$ of Asians, $52 \%$ of Hispanics and $23 \%$ of Blacks were foreign-born, in contrast to $2 \%$ of Whites [17]. In a recent national evaluation by the CDC, foreign-born black persons, mostly African and Caribbean-born, had a higher HIV diagnosis rate than native-born blacks [18].

In this current paper we found the disparity in Philadelphia to be greatest among Caribbean men. This disparity was driven in large part by a small group of Caribbean MSM. Markedly different, the prevalence rate of HIV among Caribbean women was substantially lower, suggesting a lack of overlap of sexual networks between Caribbean men and women in Philadelphia. The most common risk factor for Caribbean women was heterosexual contact.

Similar gender trends had been reported in a prevalence study conducted in LA's STD clinics. In the LA study, Caribbean men were found to have an HIV prevalence rate of $3.7 \%$, and Caribbean women $0.6 \%$ [13]. This is notable mainly in its departure from the reports of HIV prevalence by gender in the Caribbean basin, where rates among women are higher than among men [12]. Reasons for this finding of significantly lower rates in Caribbean women than in men in the US may in part reflect immigration patterns or post-immigration risk behaviors. These varying findings by region underscore the need for data by country of origin on the local level, within the larger context of national data.

For each world region, men were overrepresented among the HIVpositive compared to their representation in the population tested, and their female counterparts were conversely underrepresented. The sole exception to this pattern was the sub Saharan African cohort. For this world region, both men and women were overrepresented among the HIV-positive. African men, $1.7 \%$ of the tested, comprised $3.4 \%$ of the HIV-positive, while African women, 3.0\% of the tested, constituted $4.5 \%$ of the positive. The fact of disproportionately higher prevalence in both African men and women is consistent with data reported from the continent of Africa.

The prevalence rates in our study are lower than in many other US studies. The African population in our cohort, as in Philadelphia at large, is largely West African, unlike many other US cities reporting a larger representation of East and Southern Africans. HIV rates are considerably higher in Southern and East African countries in general than they are in West Africa [12]. Among both African men and women 
in this study, as in most other studies and reports, the predominant transmission risk was heterosexual contact.

Among the US-born population tested, prevalence rates were $0.9 \%$, $0.8 \%$ and $0.8 \%$ for black, white and Latino men respectively. For their female counterparts, rates were $0.5 \%, 0.4 \%$ and $0.3 \%$. These trends of relatively low and marginally varying rates by race and ethnicity differ substantially from national data. CDC data show that in 2007-2010, the proportion of positive HIV tests was $0.8 \%$ among blacks, $60 \%$ higher than among whites and Hispanics in 25 jurisdictions, including Philadelphia [19].

The reason for this discrepancy between our data and those reported at the national level may lie in the socioeconomic context of Philadelphia city health center patients. The majority of patients seeking care in the health centers fall into lower socioeconomic strata, and data show that in urban poverty areas the stark disparities in HIV prevalence by race and ethnicity are at best attenuated [20]. Furthermore, the classification of foreign-born blacks as African American has the potential to confound the domestic HIV epidemiology as we know it. In 2008, Kerani et al found that the percentage of blacks with HIV/ AIDS who were African-born was greater than 25\% in four of eight counties analyzed [5]. Given that the prevalence among the Africanborn is higher than in the US-born, classifying these African-born individuals as black/African American would potentially alter the HIV epidemiology reported and interpreted. We find among our cohort that the rate of HIV among US-born black men was $0.9 \%$. Including the relatively small number of African and Caribbean men, the rate among all black men was $1.2 \%$.

Disparities in HIV prevalence noted above, with the notable exception of Caribbean men, are generally not adequately explained by differences in risk behavior. For the vast majority of this global population, infection occurs in the context of practicing relatively low risk behaviors in a high prevalence setting. These findings highlight the importance of the current recommendation to normalize and routinize HIV testing as a part of regular medical care, regardless of actual or perceived risk. It also underscores the importance of understanding the contextual factors driving the epidemic $[21,22]$. For the foreign-born in this cohort, lowering risk on a population level may lie not so much in changing behaviors, but in identifying the HIV-positive and linking them to treatment. HIV pre-exposure prophylaxis (PrEP) should also be an option available to this population, given the relatively high-risk context.

For the foreign-born, routine testing, treatment and PrEP must be paired with active efforts to engage immigrant populations in care. Studies have shown that the foreign-born population is more likely to be diagnosed late than the US-born population $[14,18]$. In Philadelphia African men have been shown to be diagnosed late even in comparison with African women [23]. The foreign-born population, like any other, accesses HIV testing services only to the extent that they interface with the health care system. The foreign-born arguably face greater barriers to care including immigration status, lack of understanding of the US health care system, and cultural differences in addition to the barriers documented for US-born Americans. Hence structural methods of routine screening for this population as well as active outreach, must be seen as a critical part of our national test and treat strategy [19]. As we strive to reduce HIV disparities as required by our national HIV/AIDS strategy, the foreign-born population must be included in our planning and implementation.

\section{Conclusions}

Our findings indicate that in this US and foreign-born cohort in Philadelphia, disparities in HIV prevalence occur by world region of birth as well as by gender. These disparities are difficult to predict on the basis of risk behaviors, or the epidemic in the world regions of birth. Therefore as the US epidemic includes larger numbers of the foreignborn, data collected must include country of birth. To determine prevalence and disparities, these data must be collected not only for those identified to be HIV-positive, but also for those testing for HIV. Such data will allow us to better describe the domestic epidemic, and will serve as a first step toward more strategic allocation of resources, and better crafting of meaningful and effective prevention messages for various communities. This is an essential element of the reduction of disparities as required by the US National HIV/AIDS Strategy.

\section{Limitations}

This study has several limitations. The population studied is that accessing care in the city health centers of Philadelphia; a population largely drawn from the lower socio-economic strata. As such, these findings may not be extrapolated with any fidelity to other populations. The African cohort studied is primarily West African. The conclusions drawn about the African-born population in this study are therefore also not generalizable to those from other regions of the continent. Due to the structure of the testing program, data on acceptance rates of HIV testing were unavailable, a clear limitation of this study.

\section{Acknowledgments}

The authors would like to thank Dr. Timothy Flanigan, Chief of Infectious Diseases at the Miriam Hospital, and Dr. Kwame Dapaah-Afriyie, Director of the Hospitalist Program at the Miriam Hospital, for their review of this manuscript and for their invaluable advice and support in its preparation.

\section{References}

1. CDC (2010) Diagnoses of HIV Infection and AIDS in the United States and Dependent Areas, 2010

2. Prosser AT, Tang T, Hall HI (2012) HIV in persons born outside the United States, 2007-2010. JAMA 308: 601-607.

3. Crawford T, Caldwell G, Bush HM, Browning S, Thornton A (2012) Foreign born status and HIVIAIDS: a comparative analysis of HIVIAIDS characteristics among foreign and U.S. born individuals. J Immigr Minor Health 14: 82-88.

4. Office of National AIDS Policy (2015) National HIVIAIDS Strategy for the United States: Updated to 2020

5. Kerani RP, Kent JB, Sides T, Dennis G, Ibrahim AR, et al. (2008) HIV among African-born persons in the United States: a hidden epidemic? J Acquir Immune Defic Syndr 49: 102-106.

6. Singer A, Vitiello D, Katz M, Park D (2008) Recent Immigration to Philadelphia Regional Change in a Re-Emerging Gateway. Metropolitan Policy Program at Brookings.

7. Takenaka A, Osirim MJ (2010) Philadelphia's Immigrant Communities in Historical Perspective" in Global Philadelphia: Immigrant Communities Old and New. Temple University Press, Philadelphia, PA.

8. Unites States Census Bureau (2014) US Census Bureau State and County Quickfacts 2014

9. Foley EE (2005) HIVIAIDS and African immigrant women in Philadelphia: structural and cultural barriers to care. AIDS Care 17: 1030-1043.

10. Levy V, Prentiss D, Balmas G, Chen S, Israelski D, et al. (2007) Factors in the delayed HIV presentation of immigrants in Northern California: implications for voluntary counseling and testing programs. J Immigr Minor Health 9: 49-54.

11. Abdool Karim SS, Abdool Karim Q, Gouws E, Baxter C (2007) Global epidemiology of HIV-AIDS. Infect Dis Clin North Am 21: 1-17, vii.

12. Unaids W (2000) Report on the global HIVIAIDS epidemic. Geneva: UNAIDS/ WHO 
Citation: Kwakwa HA, Wahome R, Bessias S (2015) HIV Disparities in a US and Foreign-Born Cohort in Urban United States. J AIDS Clin Res 6: 515. doi:10.4172/2155-6113.1000515

13. Harawa NT, Bingham TA, Cochran SD, Greenland S, Cunningham WE (2002) HIV prevalence among foreign- and US-born clients of public STD clinics. Am J Public Health 92: 1958-1963.

14. Prosser AT, Tang T, Hall HI (2012) HIV in persons born outside the United States, 2007-2010. JAMA 308: 601-607.

15. MDCH (2012) Special Populations: Foreign-born persons, in 2012 Profile of HIV in Michigan (statewide). Michigan Department of Community Health.

16. Wiewel EW, Nasrallah H, Hanna D, Shepard C, Torian L, et al. (2009) HIV Diagnosis and Care Initiation Among Foreign-born Persons in New York City, 2001-2007. In Conference on Retroviruses and Opportunistic Infections, Montreal, Canada.

17. Kent JB (2005) Impact of foreign-born persons on HIV diagnosis rates among Blacks in King County, Washington. AIDS Educ Prev 17: 60-67.

18. Johnson AS, Hu X, Dean HD (2010) Epidemiologic differences between nativeborn and foreign-born black people diagnosed with HIV infection in 33 U.S. states, 2001-2007. Public Health Rep 125 Suppl 4: 61-69.
19. Centers for Disease Control and Prevention (CDC) (2011) Results of the Expanded HIV Testing Initiative--25 jurisdictions, United States, 2007-2010. MMWR Morb Mortal Wkly Rep 60: 805-810.

20. Denning P, DiNenno E (2010) Communities in crisis: is there a generalized HIV epidemic in impoverished urban areas of the United States? XVIII Internation AIDS Conference, Vienne.

21. Adimora AA, Schoenbach VJ (2002) Contextual factors and the black-white disparity in heterosexual HIV transmission. Epidemiology 13: 707-712.

22. Adimora AA, Schoenbach VJ, Doherty IA (2006) HIV and African Americans in the southern United States: sexual networks and social context. Sex Transm Dis 33: S39-45.

23. Kwakwa HA, Doggett P, Ubaldi-Rosen R, McLellan K, Gaye OH, et al. (2012) African-born men in the United States are diagnosed with HIV later than African-born women. J Natl Med Assoc 104: 14-19. 